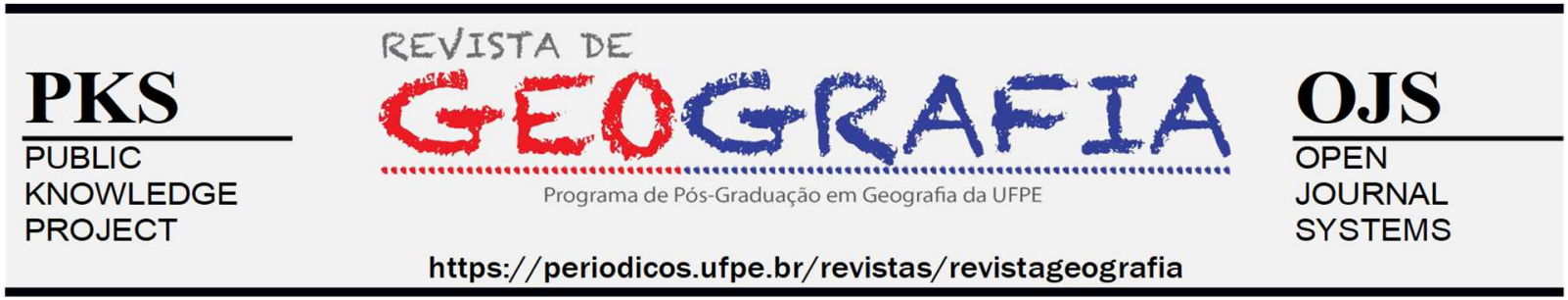

\title{
SUSCETIBILIDADE À DESERTIFICAÇÃO NA MICRORREGIÃO DE SALINAS, NORTE DE MINAS GERAIS
}

\author{
Jaíssa Bittencort de Figueiredo ${ }^{1}$, Everton Dias Amaral ${ }^{2}$, Ronaldo Medeiros dos Santos ${ }^{3}$ \\ Romildo Lopes de Oliveira ${ }^{4}$, Marcelo Rossi Vicente ${ }^{5}$
}

\footnotetext{
${ }^{1}$ Universidade Estácio de Sá, E-mail: jaissabf@ gmail.com, ORCID: https://orcid.org/0000-0002-9705-2987

${ }^{2}$ Instituto Federal Norte de Minas Gerais (IFNMG) - Campus Salinas, E-mail: evertondias094@gmail.com, ORCID: https://orcid.org/0000-0002-2361-0042

${ }^{3}$ Instituto Federal Norte de Minas Gerais (IFNMG) - Campus Salinas, E-mail: ronaldo.medeiros@ifnmg.edu.br, ORCID: https://orcid.org/0000-0003-1717-5467

${ }^{4}$ Instituto Federal Norte de Minas Gerais (IFNMG) - Campus Salinas, E-mail: romildo.oliveira@ifnmg.edu.br, ORCID: https://orcid.org/0000-0001-6596-5493

${ }^{5}$ Instituto Federal Norte de Minas Gerais (IFNMG) - Campus Salinas, E-mail: marcelo.vicente@ifnmg.edu.br, ORCID: https://orcid.org/0000-0003-2516-5656
}

Artigo recebido em 27/10/2020 e aceito em 18/06/2021

\begin{abstract}
RESUMO
No Brasil, os estados do nordeste e algumas regiões de Minas Gerais e do Espírito Santo são consideradas áreas suscetíveis à desertificação. Nessas áreas, a combinação entre fatores naturais e práticas não sustentáveis nas atividades humanas e na ocupação do espaço pode ocasionar cenários irreversíveis de degradação. Desse modo, ações diagnósticas de mapeamento são altamente relevantes, pois auxiliam a tomada de medidas preventivas ou de mitigação. No Estado de Minas Gerais, apesar de previsões dramáticas acerca do avanço da desertificação, há poucos estudos específicos para os seus municípios. Nesse contexto, o objetivo do presente trabalho consistiu em mapear a distribuição espacial da suscetibilidade à desertificação na microrregião de Salinas e identificar os fatores locais determinantes ao processo. A metodologia compreendeu a aplicação de ferramentas em sensoriamento remoto e sistemas de informações geográficas a bases de dados espaciais, para o mapeamento, via método multicritério, do processo em questão. Os resultados indicaram um predomínio de níveis baixos e moderados de suscetibilidade, com, no entanto, situações críticas específicas nos municípios de Salinas, Santa Cruz de Salinas, Rubelita, Montezuma e Santo Antônio do Retiro.
\end{abstract}

Palavras-chave: regiões áridas; degradação ambiental; uso da terra; geoprocessamento. 


\title{
DESERTIFICATION SUSCEPTIBILITY IN THE SALINAS MICRO- REGION, NORTHERN MINAS GERAIS STATE
}

\begin{abstract}
In Brazil, the northeastern states and some regions of Minas Gerais and Espírito Santo states are considered susceptible to desertification. In these areas, the combination of natural factors and unsustainable practices in human activities and land use can lead to irreversible degradation scenarios. In this way, diagnostic mapping actions are highly relevant, as they assist in taking preventive or mitigating actions. For the northern region of the State of Minas Gerais, despite dramatic predictions about the advance of desertification, there are few specific studies. In this context, the objective of the present work was to map the spatial distribution of desertification susceptibility to the microregion of Salinas and to identify the local factors determining the process. The methodology included remote sensing and geographic information systems application to spatial databases, for mapping the process, through the multicriteria method. The results indicated a predominance of low and moderate levels of susceptibility, however, with specific critical situations in the municipalities of Salinas, Santa Cruz de Salinas, Rubelita, Montezuma and Santo Antônio do Retiro.
\end{abstract}

Keywords: arid regions; environmental degradation; land use; geoprocessing.

\section{SUSCEPTIBILIDAD A LA DESERTIFICACIÓN EN LA MICROREGIÓN DE SALINAS, NORTE DE MINAS GERAIS}

\begin{abstract}
RESUMEN
En Brasil, los estados del noreste y algunas regiones de Minas Gerais y Espírito Santo se consideran áreas susceptibles a la desertificación. En estas áreas, la combinación de factores naturales y prácticas insostenibles en las actividades humanas y la ocupación del espacio puede conducir a escenarios de degradación irreversible. Por tanto, las acciones de mapeo diagnóstico son de gran relevancia, ya que ayudan a tomar medidas preventivas o de mitigación. En el Estado de Minas Gerais, a pesar de las dramáticas predicciones sobre el avance de la desertificación, existen pocos estudios específicos para sus municipalidades. En este contexto, el objetivo del presente trabajo fue mapear la distribución espacial de la susceptibilidad a la desertificación en la microrregión de Salinas e identificar los factores locales que determinan el proceso. La metodología incluyó la aplicación de herramientas en teledetección y sistemas de información geográfica a bases de datos espaciales, para el mapeo, mediante el método multicriterio, del proceso en cuestión. Los resultados indicaron un predominio de niveles bajos y moderados de susceptibilidad, sin embargo, con situaciones críticas específicas en las municipalidades de Salinas, Santa Cruz de Salinas, Rubelita, Montezuma y Santo Antônio do Retiro.
\end{abstract}

Palabras clave: regiones áridas; degradación ambiental; uso del suelo; geoprocesamiento. 


\section{INTRODUÇÃO}

As interferências antrópicas têm alterado o espaço geográfico há milênios, mas somente em meados do século XX discussões a respeito dos impactos relacionados ganharam repercussão e fórum a nível global. Uma das mais importantes questões nesse sentido diz respeito às mudanças climáticas, que, também resultantes da ação humana, segundo corrente científica majoritária, desencadeiam uma série de outros processos impactantes, dentre os quais se destaca a desertificação (TAVARES et al., 2019). Trata-se de um processo por meio do qual ocorre o empobrecimento do solo, nas zonas áridas, semiáridas e subúmidas secas, até a perda parcial ou total de sua capacidade produtiva (FERNANDES \& MEDEIROS, 2009).

Até o ano de 2016, a desertificação já ocasionava algum tipo de impacto em mais de 100 países (SILVA, 2016) e, segundo Cezário (2019), já afetou mais de 250 milhões de pessoas em todo o mundo, sobretudo populações socioeconomicamente vulneráveis de regiões em desenvolvimento, como áfrica subsaariana, Ásia e América Latina. Para Caetano et al. (2017), as principais consequências do processo em questão compreendem a degradação da situação social e econômica, devido à perda da capacidade do ambiente em oferecer recursos mínimos à sustentação da comunidade que historicamente o habita, a perda da biodiversidade e o êxodo, dentre outras. Além disso, a desertificação agrava o quadro climático, fator ao qual se associa tanto como consequência, quanto fator contribuinte (RODRIGUES et al., 2019; TAVARES et al., 2019).

No Brasil, todos os estados do nordeste e as regiões norte e noroeste, de Minas Gerais e do Espírito Santo, respectivamente, são consideradas suscetíveis à desertificação. De acordo com Silva (2016) e CGEE (2016), 1.494 municípios das referidas áreas se encontram sob algum nível de suscetibilidade, abrangendo quase 1,5 milhões de quilômetros quadrados, cerca de $16 \%$ do território brasileiro, onde habitam aproximadamente 34,8 milhões de pessoas e, consequentemente, de vidas potencialmente afetadas. Nessas áreas, a combinação entre fatores climáticos, solos e vegetação sensíveis ao processo, somados a práticas não sustentáveis na agricultura, na pecuária, na exploração dos recursos naturais e na ocupação do espaço, podem ocasionar cenários intensos, até mesmo irreversíveis, de degradação (TAVARES et al., 2017; RODRIGUES et al., 2019), motivo pelo qual ações diagnósticas são altamente relevantes, uma vez que auxiliam a tomada de medidas preventivas ou de 
mitigação. Para CGEE (2016), o mapeamento é de fundamental importância e vários estudos nesse sentido foram executados.

Mundialmente, o mapeamento das áreas sob risco de desertificação foi efetuado a partir de esforços da Convenção das Nações Unidas para o Combate à Desertificação UNCCD, tendo por base o Índice de Aridez de Thornthwaite (SAITO, 2015). No Brasil, à área mapeada segundo os critérios de suscetibilidade da UNCCD foram incluídas as zonas de entorno, como o noroeste do Espírito Santo e o nordeste do Maranhão, dentre outras. Como, no entanto, a variabilidade espacial de fatores associados ao processo é grande dentro do polígono nacional de áreas suscetíveis, esforços específicos têm sido empreendidos com o objetivo de se compreender e mapear particularidades locais estaduais ou até mesmo municipais, o que, segundo Caetano et al. (2017), contribui à identificação de medidas mitigadoras mais efetivas.

Em Tavares et al. (2017), por exemplo, o uso/cobertura da terra, com enfoque para o estado de preservação da cobertura vegetal, foi mapeado via técnicas de processamento de imagens orbitais e usado como indicador do grau de suscetibilidade à desertificação na região do Alto Sertão Sergipano, na região norte de Sergipe. Soares e Campos (2014) mapearam o índice de propensão à desertificação para uma região compreendida por 10 municípios do estado do Ceará, utilizando sistemas de informações geográficas. No mesmo estado, porém para o município de Tejuçuoca, Cezário (2019) mapeou o mesmo índice. Silva (2009) mapeou o nível de risco de desertificação para a região do semiárido pernambucano, também utilizando sensoriamento remoto e sistemas de informações geográficas. Saito (2015) utilizou as mesmas tecnologias, para identificar áreas com tendência à desertificação no estado do Espírito Santo. Em Lima et al. (2016), o mapeamento do índice de desertificação, baseado em sistemas de informações geográficas e método multicritério, contemplou uma área contígua de 32 municípios da Paraíba e do Rio Grande do Norte, na região do Seridó. Para o Estado da Bahia, Dourado (2017) mapeou cenários atuais e futuros, avindos de mudanças climáticas, do risco de desertificação, utilizando imagens de satélite, dados climáticos e edafológicos.

Para o Estado de Minas Gerais, apesar de previsões dramáticas acerca da conversão de áreas do semiárido, na região norte, em “desertos”, há poucos estudos específicos para os seus municípios, destacando-se, entre os existentes, Almeida et al. (2013) e Marques et al. (2017). No primeiro, a partir de imagens de satélite, foram estimadas as áreas, em hectares, 
suscetíveis à desertificação para cada município da área de estudo; que não abrangeu todo o perímetro mineiro considerado suscetível pela UNCCD. Outra lacuna se refere ao fato de que apenas o fator "cobertura vegetal" foi considerado no mapeamento. Por outro lado, no caso de Marques et al. (2017), o mapeamento teve um caráter regional, pois abrangeu toda a mesorregião Norte de Minas Gerais, e não levou em consideração fatores socioeconômicos, como o IDH, que são relevantes à componente antrópica do processo de desertificação (VIEIRA, 2015).

Diante do contexto ora apresentado, o objetivo do presente trabalho consistiu em mapear o grau de suscetibilidade à desertificação, em alto nível de detalhamento, para os municípios da microrregião de Salinas, e identificar os fatores locais determinantes ao processo, a partir da utilização de sensoriamento remoto, sistemas de informações geográficas e análise multicritério.

\section{MATERIAL E MÉTODOS}

A Microrregião de Salinas pertence à Mesorregião Norte do estado de Minas Gerais, localizada entre as coordenadas geográficas $41^{\circ} 19^{\prime} 19^{\prime \prime}$ e $42^{\circ} 50$ ' 02 ' de longitude oeste e $14^{\circ}$ 58'16" e 16 30'58" de latitude sul (Figura 1). Compreende uma área de 17.824 km², na qual se encontram inseridos 17 municípios - Águas Vermelhas, Berizal, Curral de Dentro, Divisa Alegre, Fruta de Leite, Indaiabira, Montezuma, Ninheira, Novorizonte, Rio Pardo de Minas, Rubelita, Salinas, Santa Cruz de Salinas, Santo Antônio do Retiro, São João do Paraíso, Taiobeiras e Vargem Grande do Rio Pardo - com população total estimada de 221.964 habitantes (IBGE, 2019).

A área de estudos é drenada pelos afluentes de três grandes rios brasileiros - o São Francisco, o Jequitinhonha e o Pardo - e, segundo Sá-Júnior (2009) e Alvares et al. (2013), se encontra sob domínio de três grupos climáticos no sistema de classificação de Köppen: Aw, nas áreas de menor altitude e ao longo da drenagem principal, com estações chuvosas (verão) e secas (inverno) bem definidas; Cwa, nas maiores altitudes da porção sul da área, com verões quentes e chuvas concentradas entre os meses de novembro e fevereiro e; Cwb, nas maiores altitudes da porção norte, ao longo da Serra do Espinhaço, de verão moderadamente quente e com as menores temperaturas médias de inverno da microrregião. As temperaturas médias anuais variam entre 20 e $24^{\circ} \mathrm{C}$ e a precipitação média anual entre 700 e $1.000 \mathrm{~mm}$. Os solos 
predominantes são os latossolos amarelos, os cambissolos e os neossolos litólicos, ocorrendo também, em áreas restritas, argissolos e neossolos flúvicos (IGAM, 2013). A vegetação natural regional é composta por fitofisionomias pertencentes aos biomas Caatinga, Cerrado e Mata Atlântica, e formações de transição, compreendendo florestas subcaducifólias, caducifólias, caatinga hiperxerófila e formações rupestres (SILVA et al., 2017; IGAM, 2013). Cerca de $57 \%$ da população da microrregião é urbana e o IDH médio é de 0,60 .

Figura 1 - Localização da área de estudo no Norte de Minas Gerais.

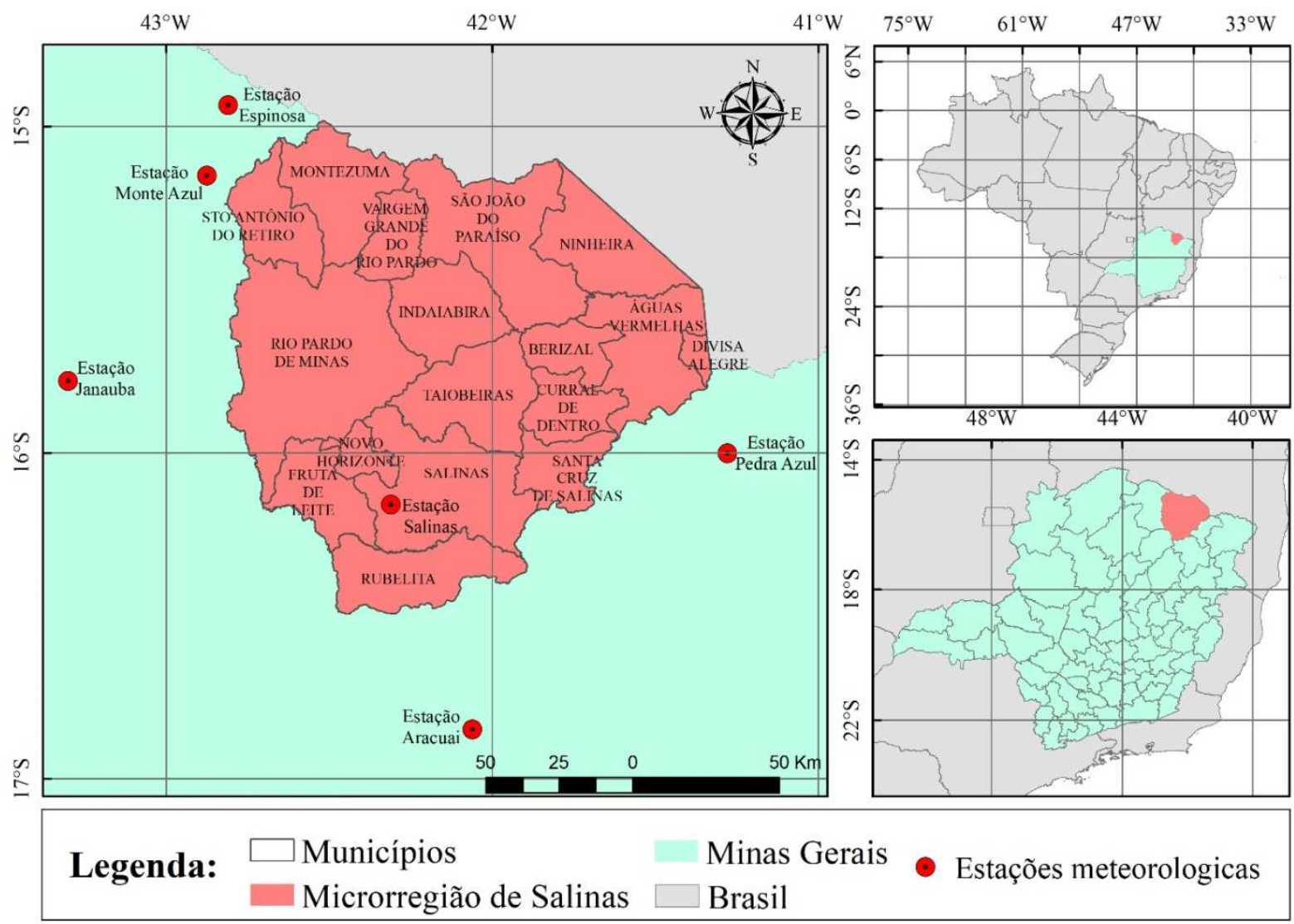

O material utilizado consistiu em imagens de satélite gratuitas LandSat-8, modelo digital de elevação - MDE gratuito SRTM com resolução espacial de 30 metros, mapas temáticos digitais gratuitos de solo, hidrografia e divisão político-administrativa, dados meteorológicos gratuitos obtidos junto ao INMET, dados socioeconômicos obtidos junto ao IBGE e softwares - Idrisi v. "Andes" licença gratuita, SPRING v.5.5.6 e QGIS 2.18 - para o processamento das informações espaciais e geração de mapas. 
A metodologia compreendeu (i) o mapeamento de cada fator associado ao processo de desertificação, (ii) o mapeamento preliminar do grau de suscetibilidade, via combinação espacial simples dos fatores, (iii) a análise espacial de sensibilidade para a estimação do "peso" de cada fator ao processo na área de estudo e (iv) o mapeamento final do grau de suscetibilidade à desertificação, via combinação espacial ponderada. Os passos metodológicos ora apresentados encontram-se sintetizados na Figura 2 e detalhados dos tópicos seguintes.

Figura 2 - Metodologia para mapeamento do grau de suscetibilidade à desertificação.

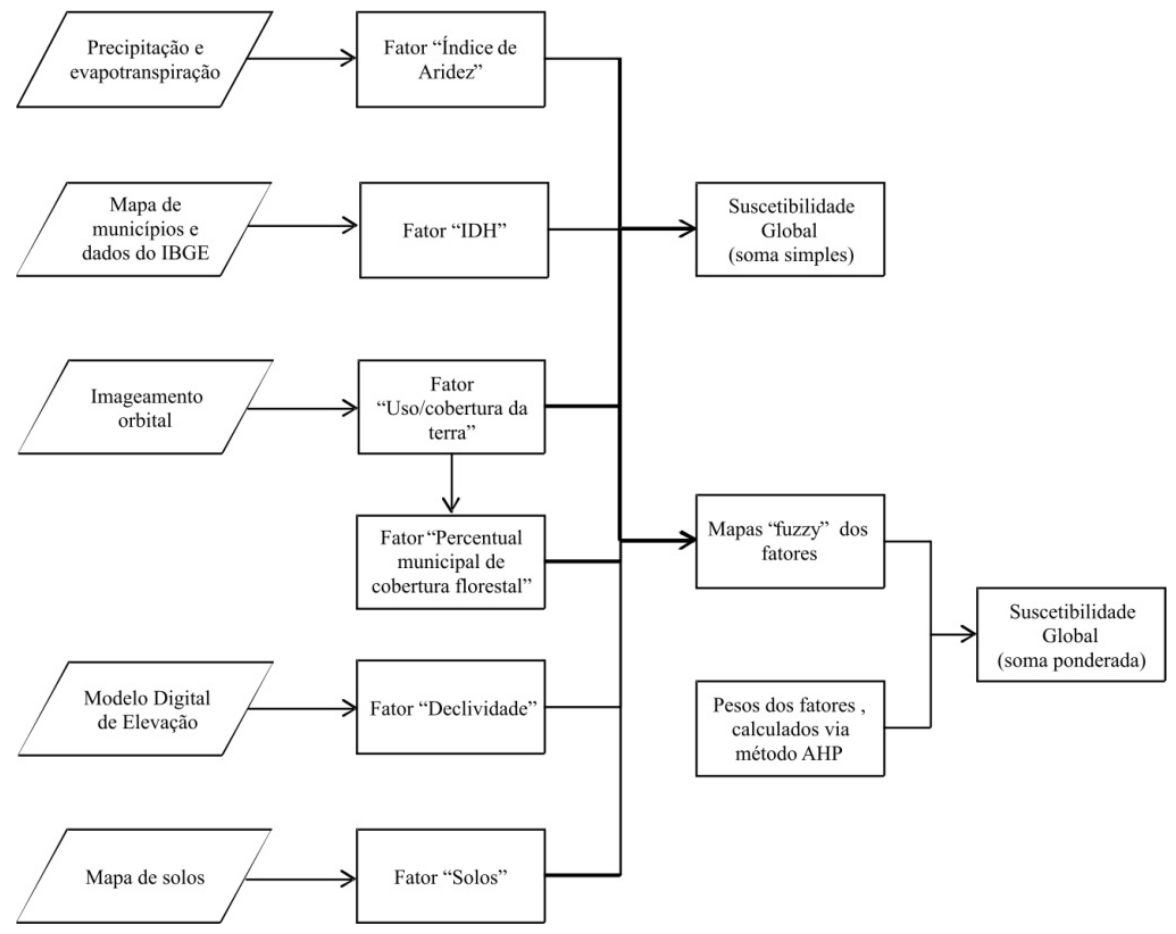

Mapeamento dos fatores associados à desertificação

Seis fatores foram considerados como sendo determinantes ao processo de desertificação na área de estudos: (i) o índice de aridez (componente climática); (ii) o Índice de Desenvolvimento Humano - IDH (componente antrópico); (iii) o Uso/cobertura da terra (componente biótico natural e antrópico); (iv) o percentual de cobertura florestal natural de cada município (componente antrópico); (v) a declividade (componente física natural); e (vi) o tipo de solo (componente física natural). 
Índice de aridez

Foram utilizados dados coletados por seis estações meteorológicas automáticas do INMET - uma localizada na área de estudos e cinco ao seu entorno. A partir das informações, foram calculadas a evapotranspiração potencial média, via método de Penman-Monteith, e a precipitação pluvial média, para os anos de 2006 a 2016. Por fim, calculou-se o índice de aridez (IA), aplicando-se o método de Thornthwaite (1948), segundo o qual a aridez de uma localidade ou região pode ser expressa pela razão entre a precipitação anual $(\operatorname{Pr})$ e a evapotranspiração potencial anual (ETP):

$$
\mathrm{Ia}=\operatorname{Pr} / \mathrm{ETP}(1)
$$

De acordo com a UNEP (1992), o IA pode variar de "hiperárido", quando menor que 0,05, a "subúmido" e "úmido", quando maior que 0,65, como apresentado na Tabela 1. Esses valores, segundo Matallo Júnior (2001), podem ser reclassificados em faixas de suscetibilidade à desertificação - Alta, Moderada e Baixa, conforme disposto na Tabela 2.

Tabela 1: Classificação do clima de acordo com o índice de aridez

\begin{tabular}{ll}
\hline Classificação & Índice de Aridez (IA) \\
\hline Hiperárido & $<0,05$ \\
Árido & 0,051 a 0,20 \\
Semiárido & 0,21 a 0,50 \\
Subúmido a seco & 0,51 a 0,65 \\
Subúmido úmido a úmido & $>0,65$ \\
\hline
\end{tabular}

Fonte: UNEP (1992).

Tabela 2: Faixas de suscetibilidade à desertificação - fator "Índice de Aridez"

\begin{tabular}{ll}
\hline Suscetibilidade à desertificação & Índice de aridez \\
\hline Alta & 0,21 até 0,50 \\
Moderada & 0,51 até 0,65 \\
Baixa & $>0,65$ \\
\hline
\end{tabular}

Fonte: Matallo Júnior (2001) adaptado.

Os valores pontuais calculados de IA para cada estação meteorológica foram espacializados via interpolação pelo método IDW, e o mapa resultante foi então reclassificado em faixas de suscetibilidade à desertificação. 
Índice de Desenvolvimento Humano

Segundo Vieira (2015), quanto menor o IDH de uma região, maior a probabilidade de que os seus habitantes não utilizem de forma sustentável o espaço e os recursos naturais do lugar. Desse modo, o autor sugere as seguintes faixas de suscetibilidade em função do IDH (Tabela 3).

Tabela 3: Faixas de suscetibilidade à desertificação - fator "IDH"

\begin{tabular}{ll}
\hline Suscetibilidade à desertificação & IDH \\
\hline Baixa & 0,70 a 1,00 \\
Moderada & 0,60 a 0,70 \\
Alta & 0 a 0,60 \\
\hline
\end{tabular}

Fonte: Vieira (2015).

Os valores de IDH de cada município da área de estudo, obtidos junto ao IBGE, foram vinculados à tabela de atributo dos polígonos de municípios, convertidos em um mapa no formato raster e reclassificado em faixas de suscetibilidade à desertificação em função do IDH.

Uso/cobertura da terra

Devido à extensão da área de estudo, foram necessárias três cenas multiespectrais Landsat-8, das quais foram selecionadas as bandas referentes à região do verde, vermelho e infravermelho próximo, do espectro eletromagnético. Para cada banda, foi confeccionado um mosaico, a partir dos quais foi gerada uma composição colorida “345" em "falsa cor", por sua vez utilizada para o reconhecimento e identificação, via fotointerpretação, das classes de uso/cobertura da terra presentes na área de estudo. Em seguida, a composição colorida foi segmentada e classificada automaticamente, utilizando-se um classificador supervisionado por regiões, gerando-se um mapa de uso/cobertura da terra, com oito classes, para a área de estudos. Os procedimentos acima descritos foram executados com o auxílio do software SPRING.

Por fim, baseando-se em Salomão (1999), o mapa de uso/cobertura da terra foi reclassificado em faixas de suscetibilidade à erosão; ora considerado um fator diretamente associado à suscetibilidade à desertificação, como disposto na Tabela 4. 
Tabela 4: Suscetibilidade à erosão a partir do uso e cobertura da terra

\begin{tabular}{ll}
\hline Uso e Cobertura & Suscetibilidade à erosão \\
\hline Floresta Estacional & Baixa \\
Cerrado & Baixa \\
Cursos D'água & Inexistente \\
Pastagem & Alta \\
Agricultura & Alta \\
Silvicultura & Moderada \\
Solo Exposto & Muito alta \\
Mata Ciliar & Baixa \\
\hline
\end{tabular}

Fonte: Salomão (1999).

Percentual de cobertura florestal natural

Também relativo à componente antrópica, foi proposto um novo fator, baseado no pressuposto lógico de que, quanto menor o percentual, em relação à área total do município, de cobertura vegetal, maior a suscetibilidade local/regional à desertificação. Segundo Prevedello et al. (2019), o desmatamento altera as características físicas da superfície, como o albedo e, consequentemente, as componentes do balanço de energia, podendo ocasionar um aumento da temperatura que se limitará não apenas à área desmatada, mas também em um raio no seu entorno. A inserção desse fator ao modelo de previsão/mapeamento da suscetibilidade à desertificação na área de estudo foi efetuada a partir da reclassificação do mapa de uso/cobertura da terra em duas classes: "floresta" e "não-floresta". Esse novo mapa foi interseccionado espacialmente com o mapa de divisão político administrativa de municípios utilizando-se uma função "zonal”, que possibilitou o cálculo da área de florestas dentro dos limites de cada município. Os valores de área foram convertidos em percentagem.

Declividade

Foram necessárias quatro cenas de MDE-SRTM para a cobertura da área de estudos, com as quais foi confeccionado um mosaico, para a sua união, o qual, por sua vez, foi submetido a um "recorte", tendo como molde um polígono referente à microrregião de Salinas e Alto Rio Pardo. Em seguida, aplicando-se a função slope, foi gerado o mapa de 
declividade, em percentagem; reclassificado em faixas de suscetibilidade à erosão - processo diretamente relacionado à suscetibilidade à desertificação - como sugerido em Francisco (2013), na Tabela 5.

Tabela 5: Faixas de risco a erosão a partir da declividade do terreno

\begin{tabular}{lll}
\hline Declive & Risco a erosão & Classes $(\%)$ \\
\hline Plano & Muito baixo & $0-3$ \\
Suavemente ondulado & Baixo & $3-6$ \\
Moderadamente ondulado & Médio & $6-12$ \\
Ondulado & Alto & $12-20$ \\
Fortemente ondulado/montanhoso & Muito alto & $>20$ \\
\hline
\end{tabular}
Fonte: Francisco (2013).

Solos

O mapa de solos foi recortado para a área de estudos, convertido para o formato raster e reclassificado em faixas de suscetibilidade à erosão de acordo com a classe, conforme o indicado por Lima et al. (2002); Salomão (1999), na Tabela 6.

Tabela 6: Risco a erosão a partir da classe de solos

\begin{tabular}{ll}
\hline Classes de solo & Suscetibilidade à erosão \\
\hline Afloramento Rochoso & Muito alto \\
Podzólico vermelho-amarelo & Muito alto \\
Solos Aluviais & Fraco \\
Terra Roxa Estruturada & Moderado \\
Cambissolo & Muito alto \\
Latossolo vermelho-amarelo & Fraco \\
Latossolo vermelho & Fraco \\
Latossolo amarelo & Fraco \\
\hline
\end{tabular}

Fonte: Lima et al. (2002); Salomão (1999)

Mapeamento do nível global de suscetibilidade à desertificação

Como a suscetibilidade global é resultante de um conjunto de fatores físico-bióticoambientais e antrópicos, foi efetuado um mapeamento preliminar da suscetibilidade à desertificação para a área de estudo considerando-se que todos os fatores ora descritos 
contribuem igualmente ao processo na região. A combinação espacial dos fatores foi efetuada por meio da calculadora de mapas, utilizando-se uma operação de soma simples, do tipo "Suscetibilidade Global $=$ Fator $1+$ Fator $2+$ Fator $3+$ Fator $4+$ Fator $5+$ Fator 6". Por se tratar de uma operação matemática, os níveis de suscetibilidade dos mapas dos fatores individuais foram convertidos em escala numérica variando entre "zero" (não suscetível) e “10” (muito suscetível). Dessa forma, no mapa resultante, o grau máximo de suscetibilidade, em escala numérica, corresponde a 60.

Por outro lado, como, segundo Caetano et al. (2017), o processo de desertificação pode ser influenciado por particularidades locais ou regionais, buscou-se um aperfeiçoamento do primeiro mapa global de suscetibilidade, a partir da incorporação, ao modelo de combinação (soma) linear simples, do elemento "ponderação", como também propõem Aquino e Oliveira (2012). Dessa forma, para a geração do novo mapa global de suscetibilidade, foi utilizado um modelo de combinação linear ponderada, do tipo "Suscetibilidade Global $=p 1 *$ Fator $1+p 2 *$ Fator $2+p 3 *$ Fator $3+p 4 *$ Fator $4+p 5 *$ Fator $5+p 6 *$ Fator 6", em que $p i=$ peso, ou grau de importância, do fator "i”".

Uma forma clássica de se calcular os pesos dos fatores é por meio de consulta a especialistas no assunto. No entanto, também é possível estimá-los a partir de consultas à literatura e conhecendo-se adequadamente as particularidades da área de estudo, a partir do que os fatores podem ser comparados entre si, por meio de uma matriz de comparação, e numericamente ranqueados. Tal procedimento consiste, na verdade, em uma técnica de análise multicritério denominada AHP - Analytic Hierarchy Process. Mas antes desse cálculo, foi necessário padronizar e escalonar os valores numéricos dos mapas dos fatores, que no Idrisi, software utilizado para essa etapa metodológica, é executado por meio de funções fuzzy. Nessa operação, os valores numéricos dos fatores foram convertidos em uma nova escala de grandeza, normalizada e ordenada de acordo com uma preferência definida à priori. No presente trabalho, para fatores com relação direta à suscetibilidade à desertificação, utilizou-se a função sigmoidal crescente (Figura 3a), enquanto que para os casos de relação inversa adotou-se a função sigmoidal decrescente (Figura 3b). Nas abscissas têm-se os limiares da escala numérica original dos fatores e nas ordenadas o valor assumido na escala fuzzy. 
Figura 3 - Funções fuzzy utilizadas para padronização e escalonamento dos fatores de suscetibilidade

(A)

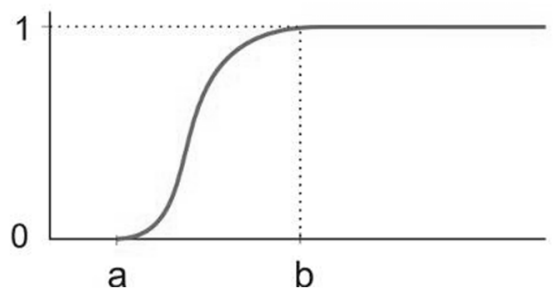

(B)

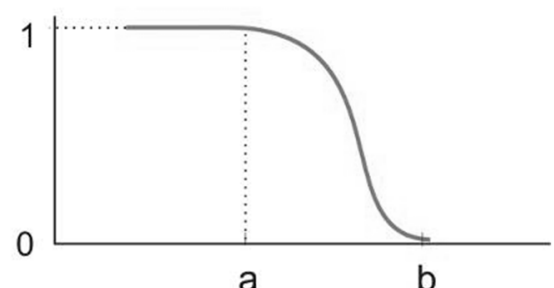

Fonte: Santos (2012).

Após gerados os mapas fuzzy, procedeu-se ao cálculo dos pesos dos fatores. Segundo Santos (2012), no método AHP, a matriz de comparação "par-a-par" dos fatores " $f i$ ” (Figura 4) é preenchida comparando-se cada linha a cada coluna, individualmente, atribuindo-se um valor numérico equivalente à importância relativa do fator da linha " $i$ " em relação ao fator da coluna “j”, segundo a escala apresentada na Tabela 7.

Figura 4 - Matriz de comparação AHP

\begin{tabular}{|c|c|c|c|c|c|}
\hline & $\mathbf{f}_{\mathbf{1}}$ & $\mathbf{f}_{\mathbf{2}}$ & $\mathbf{f}_{\mathbf{3}}$ & $\mathbf{f}_{\mathbf{4}}$ & $\mathbf{f}_{\mathrm{u}}$ \\
\hline $\mathbf{f}_{\mathbf{1}}$ & $\mathbf{1}$ & & & & \\
\hline $\mathbf{f}_{2}$ & $?$ & $\mathbf{1}$ & & & \\
\hline $\mathbf{f}_{3}$ & $?$ & $?$ & $\mathbf{1}$ & & \\
\hline $\mathbf{f}_{4}$ & $?$ & $?$ & $?$ & $\mathbf{1}$ & \\
\hline $\mathbf{f}_{\mathrm{n}}$ & $?$ & $?$ & $?$ & $?$ & $\mathbf{1}$ \\
\hline
\end{tabular}

Fonte: Santos (2012).

Tabela 7: Escala de julgamento AHP.

\begin{tabular}{l|c|c|c|c|c|c|c|c|c}
\hline Valor & $1 / 9$ & $1 / 7$ & $1 / 5$ & $1 / 3$ & 1 & 3 & 5 & 7 & 9 \\
\hline significado & extremo & $\begin{array}{c}\text { muito } \\
\text { forte }\end{array}$ & forte & moderado & igual & moderado & forte & $\begin{array}{c}\text { muito } \\
\text { Forte }\end{array}$ & extremo \\
\hline & Menos importante
\end{tabular}

Fonte: Santos (2012), adaptado de Silvério (2006).

A atribuição dos valores na matriz de comparação (Figura 4) se baseou (i) no conhecimento da área de estudo, (ii) em consulta à literatura e (iii) em uma análise de sensibilidade do modelo de combinação linear simples aos fatores considerados. A análise de sensibilidade foi efetuada variando-se individualmente o valor de cada fator (mapa) em 50\%, 
em relação ao seu valor original e, em seguida, efetuando-se a soma simples dos fatores, com o valor alterado do fator testado, um por vez, observando o impacto da variação do fator da vez ao resultado final (nível global de suscetibilidade). Tal operação foi repetida para todos os seis fatores. Ainda nessa etapa, seguindo o recomendado em Silvério (2006), com o objetivo de se reduzir a tendenciosidade no processo de estimação dos pesos globais, optou-se por adotar valores moderados de importância, na comparação "par-a-par" entre os fatores. A partir dos valores da matriz de comparação, foram estimados os pesos globais de cada fator no grau de suscetibilidade à desertificação, utilizando-se o módulo "Decision Support - Weight", do Idrisi. Por último, com os mapas fuzzy dos fatores e os seus respectivos pesos calculados, foi gerado o segundo mapa de suscetibilidade à desertificação, via combinação linear ponderada.

\section{RESULTADOS E DISCUSSÃO}

Na Figura 5, encontram-se apresentados os mapas parciais de suscetibilidade à desertificação, em função dos seis fatores considerados. Na Figura 6 é apresentado o primeiro mapa do nível global de suscetibilidade; resultado obtido a partir da combinação linear simples (soma) dos mapas parciais. 
Figura 5 - Níveis "parciais” de suscetibilidade à desertificação em função dos fatores considerados.

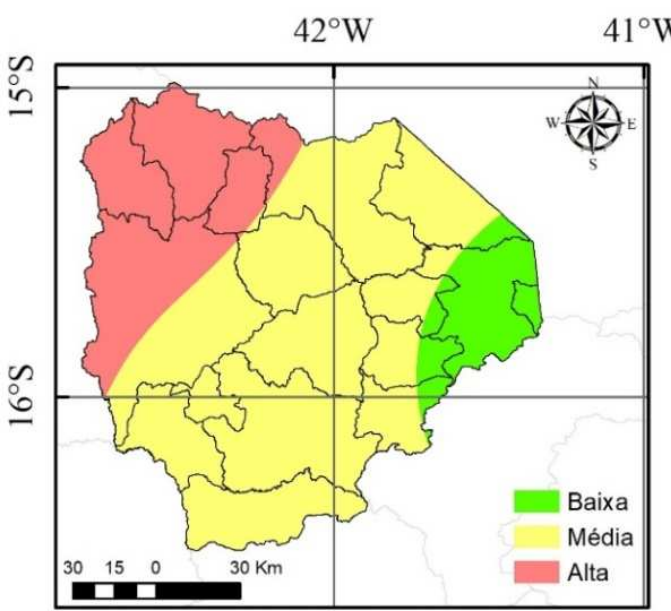

Fator "Índice de Aridez"

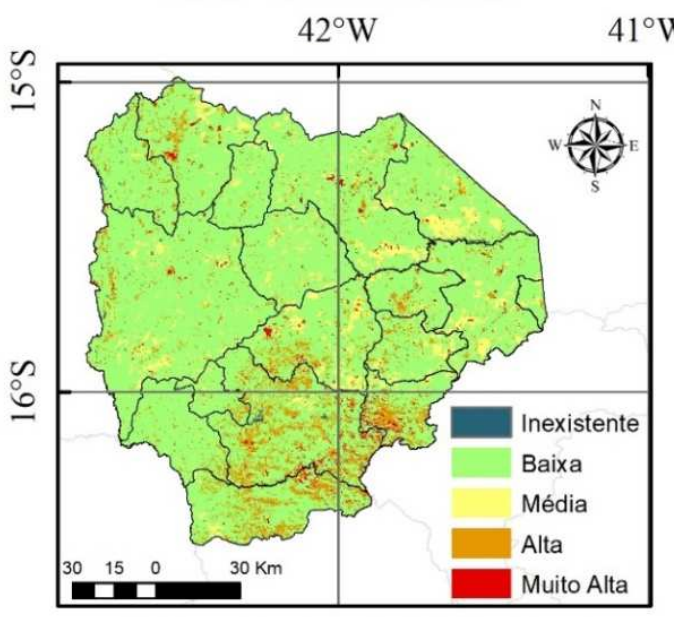

Fator "Uso/Cobertura da Terra"

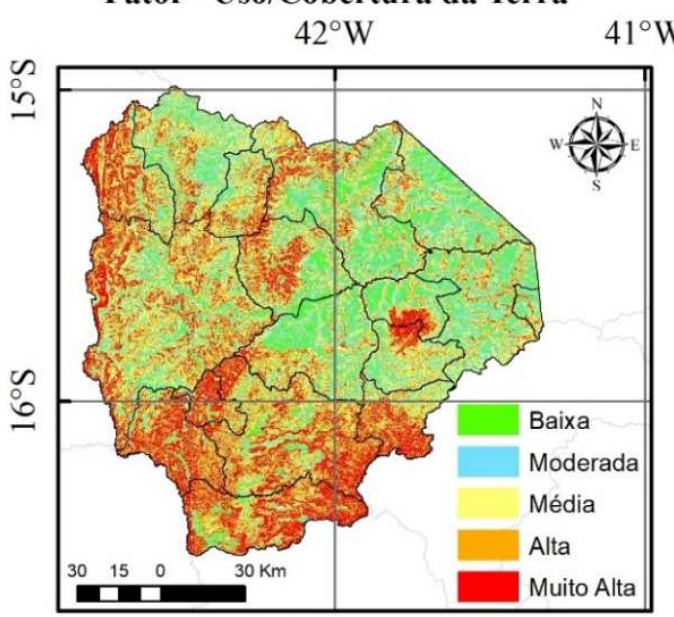

Fator "Declividade"

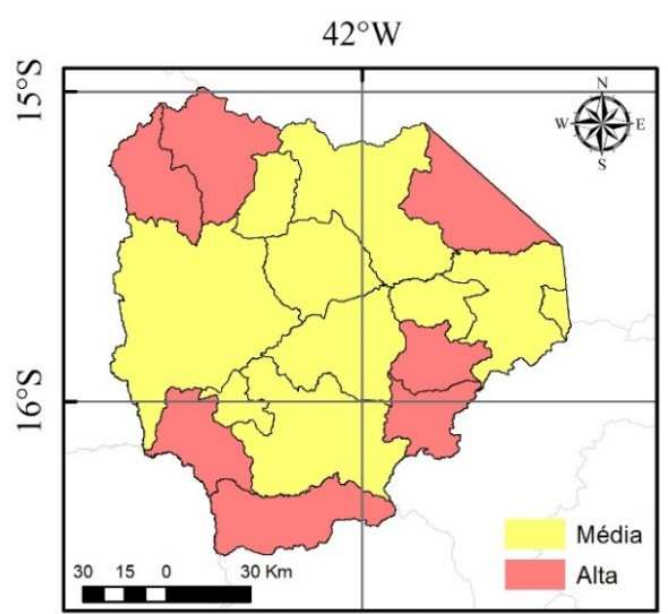

Fator "IDH"

$42^{\circ} \mathrm{W}$

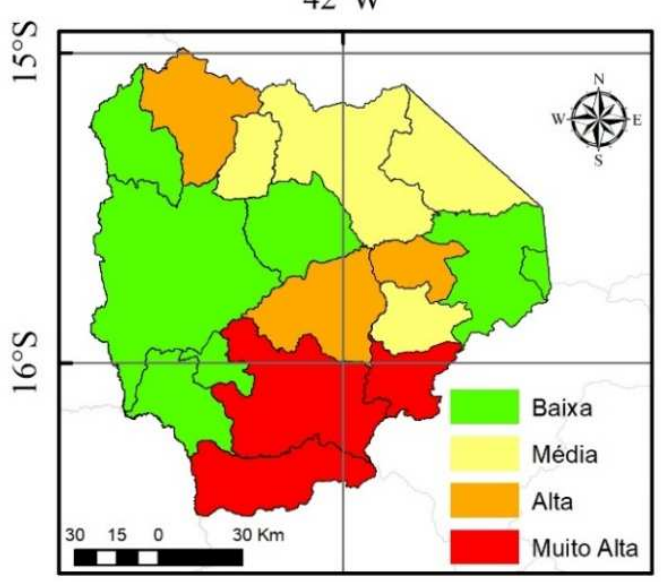

Fator "\% Cobertura Florestal" $42^{\circ} \mathrm{W}$

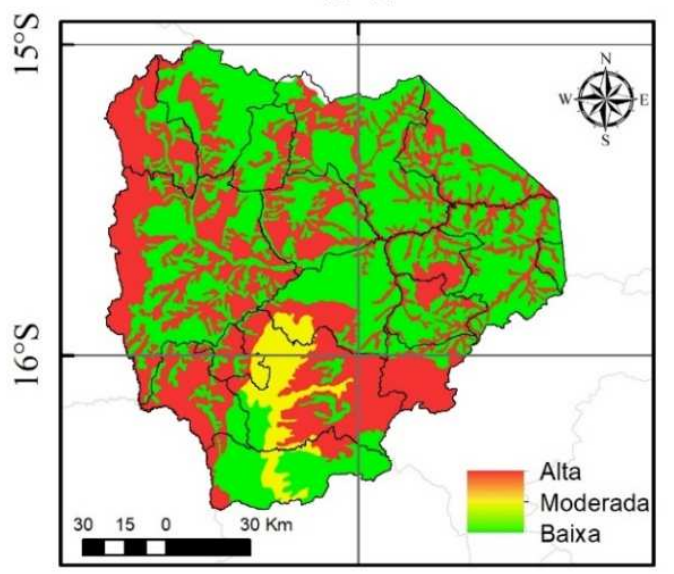

Fator "Solo"

Sistema de Coordenadas Geográficas Datum: SIRGAS 2000 
Figura 6 - Nível global de suscetibilidade à desertificação: combinação linear por soma simples.

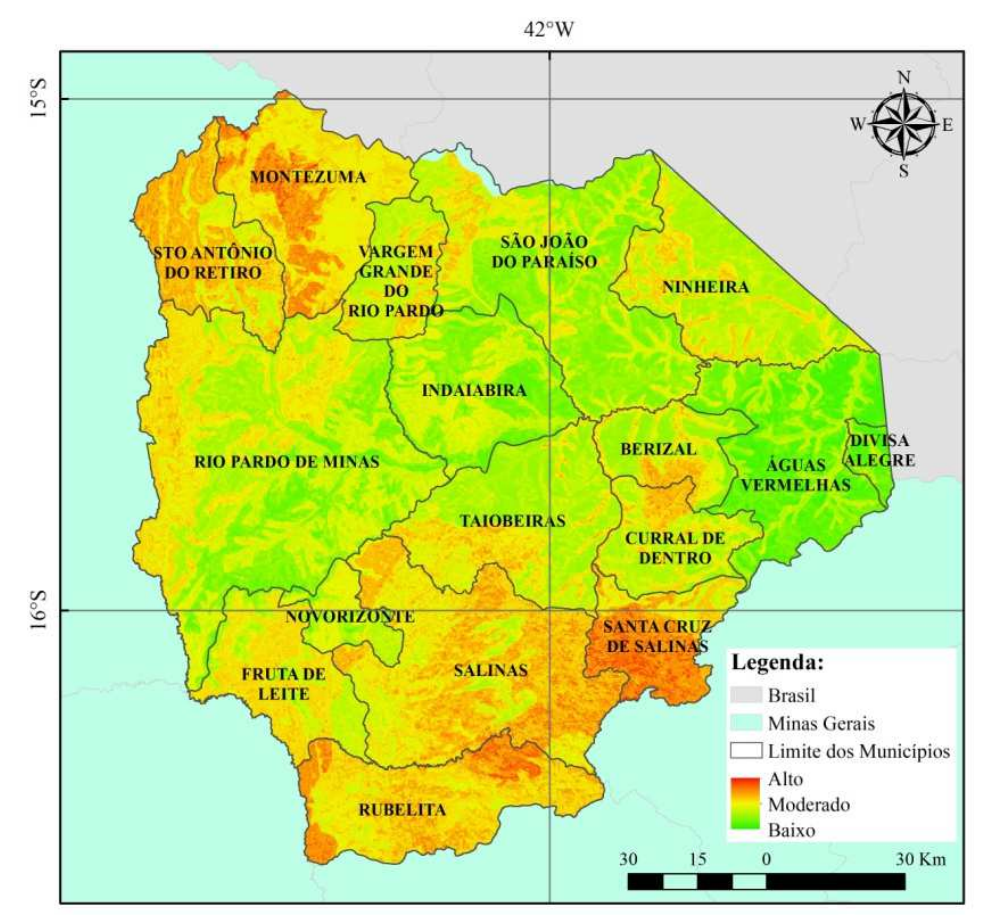

Considerando que cada fator relacionado ao processo de desertificação possui igual nível de importância, as áreas sob o maior grau de suscetibilidade se distribuem predominantemente nas porções noroeste e sul da área de estudo, notadamente nos municípios de Montezuma, Santo Antônio do Retiro, Vargem Grande do Rio Pardo, Santa Cruz de Salinas, Salinas e Rubelita. A explicação para tal resultado pode estar relacionada ao fato de que, nessas áreas, houve um predomínio "cruzado" de alta suscetibilidade parcial referente a fatores com distribuição espacial de caráter fortemente regional, como o Índice de Aridez, o IDH, o Percentual Municipal de Cobertura Florestal e o fator Solo. Dessa forma, considera-se que, se os pesos dos fatores forem iguais, em um modelo linear de soma simples a distribuição espacial "em bloco" de alguns fatores pode influenciar sobremaneira o resultado final.

O fator "Índice de Aridez", por exemplo, responsável pela alta suscetibilidade de uma larga faixa ao noroeste, não necessariamente, por si só, implica em uma alta suscetibilidade geral real da área, uma vez que outros fatores ambientalmente favoráveis e a própria resiliência dos ecossistemas podem, em condições de campo, atenuar ou até mesmo anular o efeito individual do referido fator. Essa análise reforça a importância das 
componentes antrópicas no processo de desertificação, que alteram o ambiente e, consequentemente, sua capacidade de recuperação e adaptação, a velocidades geralmente maiores que as da dinâmica natural da paisagem (CGEE, 2016). Apesar das deficiências do modelo utilizado para a geração do resultado em discussão, o resultado foi coerente em relação ao alcançado em Almeida et al. (2013) e por Marques et al. (2017), embora, nesse último caso, os níveis baixos e médios de suscetibilidade tenham predominado na microrregião de Salinas e Alto Rio Pardo.

Após consultas à literatura, reflexões acerca de particularidades da área de estudos, análise de sensibilidade do modelo linear de soma simples, e aplicação do método AHP para ranqueamento dos fatores e estimação dos seus pesos, sugere-se que o ordenamento e os coeficientes de ponderação (pesos) que melhor indicariam o grau de importância dos fatores na suscetibilidade à desertificação na área de estudos seriam: $\left(1^{\circ}\right)$ Uso/cobertura da terra 0,4100; $\left(2^{\circ}\right)$ Percentual municipal de cobertura florestal natural - 0,2736; $\left(3^{\circ}\right)$ Solos $-0,1530$; $\left(4^{\circ}\right)$ Índice de aridez - 0,0863; $\left(5^{\circ}\right)$ Declividade - 0,0495 e; $\left(6^{\circ}\right)$ IDH - 0,0276. Aplicando-se os coeficientes de ponderação à soma dos mapas fuzzy dos fatores, obteve-se o mapa “aperfeiçoado" de suscetibilidade, apresentado na Figura 7.

Figura 7 - Mapa final (por soma ponderada) do grau de suscetibilidade à desertificação.

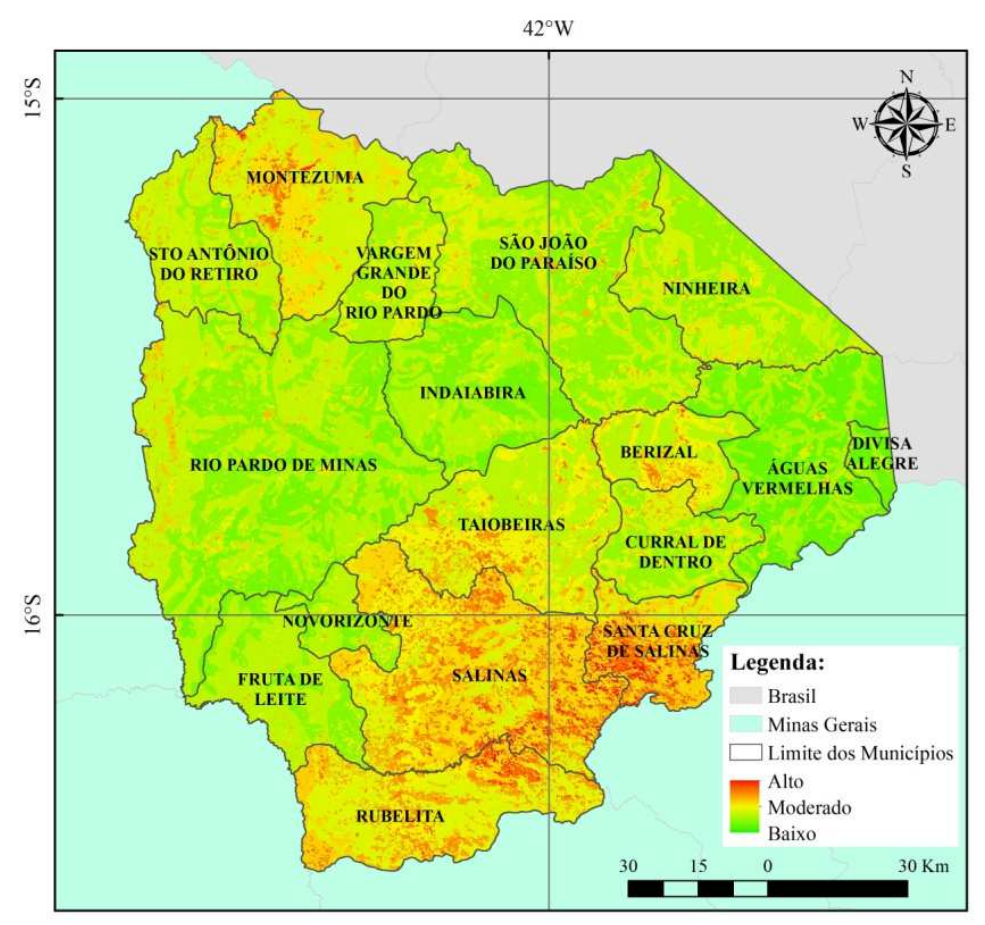


Foi observado que a distribuição espacial dos níveis mais altos de suscetibilidade se manteve, em comparação ao primeiro mapa obtido via soma simples, com os municípios de Montezuma, Santa Cruz de Salinas, Salinas e Rubelita representando os cenários mais críticos, com maior percentual de áreas sob alto grau de suscetibilidade. No entanto, percebe-se agora no mapa "aperfeiçoado", que o padrão contíguo anterior, com grandes blocos resultantes da igualdade de pesos e da distribuição espacial regional de alguns fatores, como o IDH e o Índice de Aridez, por exemplo, se "diluiu", dando lugar a um padrão espacial mais fragmentado - efeito direto de uma maior importância relativa do "Uso/cobertura da terra", considerado também por Ferreira et al. (2014) como sendo o fator de maior influência no processo de desertificação.

As maiores mudanças do mapa aperfeiçoado em relação ao mapa de soma simples ocorreram em Montezuma e Santo Antônio do Retiro, com a redução dos valores extremos de suscetibilidade. O mesmo ocorreu, porém no sentido de alteração "moderado" para "baixo", nos municípios de Rio Pardo de Minas, Fruta de Leite, Indaiabira e Novorizonte. Essa redução dos valores extremos e predomínio de valores moderados e baixos de suscetibilidade foi considerada uma melhoria no modelo de mapeamento, pois foi ao encontro do resultado alcançado por Marques et al. (2017). Além disso, o mapa "aperfeiçoado" apresentou um maior nível de detalhes que o encontrado por esses autores. Em Montezuma, por exemplo, o cenário crítico (altas suscetibilidades) mapeado no presente trabalho é mais coerente às condições reais observadas em campo, pois, de acordo com relatos de técnicos e de moradores, existem nesse município grandes porções de áreas extremamente degradadas, localmente denominadas "peladores", sem cobertura vegetal e de solos altamente compactados.

Quanto à situação de cada município em relação à desertificação, o cenário observado visualmente no mapa final pode ser confirmado por meio dos valores de área e de percentual ocupados por cada nível mapeado de suscetibilidade, apresentados na Tabela 8.

Os municípios de Rubelita, Salinas e Santa Cruz de Salinas foram os que apresentaram o maior percentual de área sob "alto nível" de suscetibilidade, com 23,8\%, 27,5\% e $27,6 \%$, respectivamente, de percentual em relação às suas extensões totais. A maior parte dos municípios, no entanto, se encontra sob predomínio de suscetibilidade moderada e baixa, corroborando Marques et al. (2017), com os municípios de Ninheira, Águas Vermelhas e 
Divisa Alegre apresentando os melhores cenários (maior percentual de áreas sob baixa e moderada suscetibilidade).

Dos municípios abrangidos pelo presente trabalho, sete coincidiram com os estudados em Almeida et al. (2013) - Montezuma, Rio Pardo de Minas, São João do Paraíso, Vargem Grande do Rio Pardo, Santo Antônio do Retiro, Ninheira e Indaiabira - que quantificaram as áreas sob alta suscetibilidade nos municípios da região semiárida do Norte de Minas Gerais. Embora os valores de área estimados por esses autores divergem em relação aos calculados no presente trabalho, o ordenamento desses municípios quanto à criticidade foi convergente. Como Almeida et al. (2013) se basearam apenas no Índice de Vegetação da Diferença Normalizada - NDVI, calculado a partir de imagens do sensor MODIS (resolução espacial de $250 \mathrm{~m}$ ), as estimativas de área do presente trabalho foram consideradas mais precisas.

Tabela 8 - Distribuição superficial e percentual do grau de suscetibilidade nos municípios da microrregião de Salinas e Alto Rio Pardo.

\begin{tabular}{|c|c|c|c|c|c|c|c|}
\hline \multirow[t]{2}{*}{ Município } & \multirow{2}{*}{$\begin{array}{l}\text { Área Total } \\
\qquad\left(\mathrm{km}^{2}\right)\end{array}$} & \multicolumn{2}{|c|}{ Baixa Suscet. } & \multicolumn{2}{|c|}{$\begin{array}{c}\text { Moderada } \\
\text { Suscet. }\end{array}$} & \multicolumn{2}{|c|}{ Alta Suscet. } \\
\hline & & $\mathrm{Km}^{2}$ & $\%$ & $\mathrm{Km}^{2}$ & $\%$ & $\mathrm{Km}^{2}$ & $\%$ \\
\hline Águas Vermelhas & 1.263 & 1179 & 93,4 & 80 & 6,3 & 3 & 0,3 \\
\hline Berizal & 490 & 122 & 24,9 & 340 & 69,5 & 27 & 5,6 \\
\hline Curral de Dentro & 570 & 247 & 43,4 & 314 & 55,1 & 8 & 1,5 \\
\hline Divisa Alegre & 118 & 111 & 93,9 & 7 & 5,9 & 0 & 0,0 \\
\hline Fruta de Leite & 764 & 367 & 48,1 & 394 & 51,6 & 1 & 0,2 \\
\hline Indaiabira & 1.006 & 817 & 81,3 & 187 & 18,6 & 2 & 0,2 \\
\hline Montezuma & 1.132 & 2 & 0,2 & 1055 & 93,2 & 74 & 6,5 \\
\hline Ninheira & 1.111 & 590 & 53,1 & 516 & 46,5 & 4 & 0,4 \\
\hline Novorizonte & 272 & 169 & 62,1 & 101 & 37,2 & 2 & 0,7 \\
\hline Rio Pardo de Minas & 3.121 & 1811 & 58,0 & 1295 & 41,5 & 13 & 0,4 \\
\hline Rubelita & 1.112 & 1 & 0,1 & 845 & 76,0 & 265 & 23,8 \\
\hline Salinas & 1.865 & 1 & 0,0 & 1351 & 72,4 & 513 & 27,5 \\
\hline Santa Cruz de Salinas & 591 & 1 & 0,1 & 427 & 72,2 & 163 & 27,6 \\
\hline $\begin{array}{l}\text { Santo Antonio do } \\
\text { Retiro }\end{array}$ & 797 & 178 & 22,4 & 614 & 77,0 & 4 & 0,5 \\
\hline São João do Paraíso & 1.929 & 1090 & 56,5 & 831 & 43,1 & 8 & 0,4 \\
\hline Taiobeiras & 1.222 & 164 & 13,4 & 954 & 78,0 & 105 & 8,6 \\
\hline $\begin{array}{l}\text { Vargem Grande do } \\
\text { Rio Pardo }\end{array}$ & 492 & 278 & 56,6 & 207 & 42,1 & 6 & 1,3 \\
\hline
\end{tabular}


Em relação às áreas ao longo da porção extremo oeste dos municípios de Rio Pardo de Minas e Santo Antônio do Retiro, os níveis moderados e altos de suscetibilidade não necessariamente refletem as condições de campo, uma vez que a marcante presença de afloramentos rochosos, de vegetação esparsa campestre natural e de altas declividades influenciaram fortemente o resultado do modelo para as referidas áreas - em grande parte preservadas, pertencentes ao Parque Estadual de Serra Nova e Talhado. Nessas áreas, acredita-se que a manutenção das condições naturais de cobertura da terra confere resiliência à desertificação.

\section{CONSIDERAÇÕES FINAIS}

O objetivo desse trabalho compreendeu o diagnóstico da microrregião de Salinas e Alto Rio Pardo quanto à suscetibilidade à desertificação, a partir do seu mapeamento e da identificação de fatores locais determinantes. A partir dos resultados e das discussões efetuadas sobre os mesmos, concluiu-se que:

- de maneira geral, a região se encontra predominantemente sob níveis baixos e moderados de suscetibilidade;

- áreas sob alta suscetibilidade, de extensão considerável (acima de $100 \mathrm{~km}^{2}$ ), foram mapeadas em Montezuma, Santo Antônio do Retiro, Vargem Grande do Rio Pardo, Santa Cruz de Salinas, Salinas e Rubelita (situação mais crítica nesses três últimos). Apesar de não terem sido efetuados trabalhos de campo, a existência de tais áreas foi confirmada por relatos de técnicos de órgãos públicos e moradores da região;

- dentre os fatores considerados, o mais importante ao processo na região foi o "uso/cobertura da terra", seguido por "percentual municipal de cobertura florestal natural”, "solos", "índice de aridez", "declividade" e "IDH";

- a incorporação dos coeficientes de ponderação ao modelo de soma simples resultou em uma maior consistência do mapeamento, uma vez que a distinção quanto aos diferentes graus de importância dos fatores no processo confere ao modelo, empírico, maior verossimilhança física;

- o mapeamento final alcançado apresentou maior nível de detalhamento espacial que o de trabalhos existentes para a área de estudos; tornando-o mais adequado, como informação básica de partida, à proposição de medidas locais de enfrentamento ao problema da desertificação; 
- os estudos deverão ser refinados, com a avaliação e revisão dos valores estimados para os pesos dos fatores, e com a execução de trabalhos de campo, com o objetivo de se checar a acurácia do mapeamento e de identificar a existência de focos de desertificação já estabelecidos.

\section{REFERÊNCIAS}

ALMEIDA, R. P.; NERY, C. V. M.; LIMA, F. A. Uso do sensoriamento remoto para estudo da susceptibilidade ao processo de desertificação na região semiárida do norte de minas gerais. Caminhos de Geografia, Uberlância, v. 14, n. 47, p.162-168, Set/2013.

AQUINO, C. M. S. de; OLIVEIRA, J. G. B. de. Avaliação de indicadores biofísicos de degradação/desertificação no núcleo de São Raimundo Nonato, Piauí, Brasil. Revista Equador, UFPI, v. 1, n. 1, p. 44-59, Jun./Dez. 2012.

CAETANO, F. A. de O.; GONÇALVES, D. de S. L.; FEITOSA, M. M.; TEIXEIRA, R. N.; LEMOS, J. de J. S. Desertificação no Nordeste brasileiro: uma análise das vulnerabilidades socioeconômicas do município de Irauçuba-CE. Revista Espacios, v.38, n.39, p.14-35, 2017, ISSN: 0798-1015.

CENTRO DE GESTÃO E ESTUDOS ESTRATÉGICOS - CGEE. Desertificação, degradação da terra e secas no Brasil. Brasília, DF: 2016. 252p.

CEZÁRIO, A. R. V. Degradação ambiental e susceptibilidade à desertificação no município de Tejuçuoca, Ceará - Brasil. Dissertação de Mestrado. Dissertação (Mestrado em Geografia) - Programa de Pós-Graduação em Geografia, Universidade Federal do Ceará, Fortaleza - CE, 2019.

DOURADO, C. da S. Áreas de risco de desertificação atuais e futuros frente às mudanças climáticas. Tese (Doutorado em Engenharia Agrícola) - Faculdade de Engenharia Agrícola, Universidade Estadual de Campinas, Campinas - SP, 2017.

FERNANDES, J. D.; DE MEDEIROS, A. J. D. Desertificação no Nordeste: uma aproximação sobre o fenômeno do Rio Grande Norte. Holos, v. 3, p. 147-161, 2009.

FERREIRA, P. S.; GOMES, V. P.; SANTOS, A. M.; MORAIS, Y. C. B.; MIRANDA, R. Q.; FERREIRA, J. M. S.; GALVÍNCIO, J. D. Análise do cenário de suscetibilidade à desertificação na bacia hidrográfica do rio Pajeú-Estado de Pernambuco. Scientia Plena, v. 10, n. 10, p. 1-11, 2014.

FRANCISCO, P. R. M. Modelo de mapeamento da deterioração do Bioma Caatinga da bacia hidrográfica do Rio Taperoá, PB. 2013. Tese (Doutorado em Engenharia Agrícola). Centro de Tecnologia e Recursos Naturais, Universidade Federal de Campina Grande, 2013. 
IBGE - Instituto Brasileiro de Geografia e Estatística. Censo Demográfico. Rio de Janeiro, 2019. Disponível em <https://www.ibge.gov.br/>. Acesso em 14 de jun. de 2020.

IGAM - Instituto Mineiro de Gestão das Águas. Fase I - Diagnóstico integrado do meio físico-biótico, antrópico e das disponibilidades e demandas hídricas - Plano diretor de recursos hídricos da bacia hidrográfica dos afluentes mineiros do rio Pardo. Belo Horizonte, 2013. 728 p.

JÚNIOR, H. M. Indicadores de desertificação: histórico e perspectivas. Cadernos UNESCO, Brasília, 2001. 80p.

LIMA, A. A. C.; OLIVEIRA, F. N. S.; AQUINO, A. R. L. de. Limitações do uso dos solos do Estado do Ceará por suscetibilidade à erosão. Fortaleza: Embrapa Agroindústria Tropical, 2002. 19p. (Embrapa Agroindústria Tropical. Documentos, 54).

LIMA, R. DA C. C.; CURI, W. F.; SANTOS, A. P. S. DOS; COSTA, T. S. P. DA S. Sistema de avaliação espacial do processo de desertificação no semiárido brasileiro. Gaia Scientia, v. 10, n. 4, 19 dez. 2016.

MARQUES, M. V. A.; MOREIRA, A. A.; NERY, C. V. M. Diagnóstico da desertificação na região norte de minas gerais por meio de técnicas de geoprocessamento. Boletim de Geografia, Maringá, v. 35, n. 2, 2017.

PREVEDELLO, J. A.; WINCK, G. R.; WEBER, M. M.; NICHOLS, E.; SINERVO, B. Impacts of forestation and deforestationon local temperature across the globe. PloS One, v. 14, n. 3, pág. e0213368, 2019.

RODRIGUES, T. M. de F.; SENNA, M. C. A.; CATALDI, M. Simulação dos impactos climáticos da desertificação do Nordeste brasileiro. Engenharia Sanitária e Ambiental, Cabo Frio, v. 24, n. 5, p. 1037-1047, set/out 2019.

SAITO, N. S. Identificação de áreas com tendência a desertificação no estado do Espírito Santo com o auxílio de geotecnologias. 2015. Tese (Doutorado em Sensoriamento Remoto) - Instituto Nacional de Pesquisas Espaciais, Espaciais, São José dos Campos, 2015. Disponível em:<http://urlib.net/8JMKD3MGP3W34P/3KABML2>. Acesso em 13 de maio de 2020.

SALOMÃO, F. X. T. Controle e prevenção dos Processos Erosivos. In GUERRA, A. J. T.; SILVA, A. S.; BOTELHO, R. G. M. (Orgs.) Erosão e Conservação dos Solos: Conceitos, Temas e Aplicações. Rio de Janeiro: Bertrand Brasil, 2010. P. 229-268.

SANTOS, R. M. dos. Recarga de Águas Subterrâneas em Ambiente de Cerrado: Estudo com base em modelagem numérica e simulação hidrológica em uma bacia experimental. 2012. Tese (Doutorado em Tecnologia Ambiental e Recursos Hídricos). Faculdade de Tecnologia, Departamento de Engenharia Civil e Ambiental, Universidade de Brasília, Brasília - DF, 2012. 
SILVA, H. P. da. Mapeamento das áreas sob risco de desertificação no semiárido de Pernambuco a partir de imagens de satélites. 2009. 153f. Tese (Doutorado em Ciências do Solo). Universidade Federal Rural de Pernambuco, Departamento de Agronomia, Recife. 2009.

SILVA, M. C. Degradação ambiental e áreas susceptíveis à desertificação antrópica no município sergipano de Nossa Senhora da Glória. 2016. Dissertação de Mestrado. Dissertação (Mestrado em Geografia) - Programa de Pós-Graduação em Geografia, Universidade Federal de Sergipe, São Cristóvão - SE, 2016.

SILVA, R. DE J.; CHIAPETTI, R. J. N.; ARAÚJO, G. S. DE. Atlas físico da bacia hidrográfica do rio Pardo para uso escolar. Revista de Ensino de Geografia, Uberlândia, v. 8, n. 14, p. 67-93. Jan./Jul. 2017. ISSN 2179-4510.

SILVÉRIO, JÚNIOR, J. Aplicação do Método Analytic Hierarchy Process na Avaliação de Indicadores Setoriais de Arranjos Produtivos Locais: Caso do APL de Madeira e Móveis de Paragominas - PA. 2006. Dissertação (Mestrado em Economia de Empresas) Universidade Católica de Brasília, Brasília-DF, 2006.

SOARES, R. B.; CAMPOS, K. C. Índice de propensão à desertificação no Estado do Ceará. Revista Teoria e Evidência Econômica, v. 20, n. 42, p. 139-156, Jan./Jun. 2014.

TAVARES, K. C. O.; CRUZ, A. S.; LIRA, D. R.; SANTOS, C. A. Identificação de áreas susceptíveis a desertificação do Alto Sertão Sergipano. In: XVII Simpósio Brasileiro de Geografia Aplicada, 2017, Campinas - SP. Anais. Campinas: Unicamp, 2017. v.1, p.56165620 .

TAVARES, V. C.; ARRUDA, Í. R. P.; SILVA, D. G. Desertificação, mudanças climáticas e secas no semiárido brasileiro: uma revisão bibliográfica. Geosul, Florianópolis, v. 34, n. 70, p. 385-405, Jan./Abr. 2019.

THORNTHWAITE, C.W. An approach toward a rational classification of climate. Geographical Review, New York, v.38, n.1, p.55-94, Jan. 1948.

UNEP - UM ENVIRONMENT PROGRAME. Convention on Biological Diversity. UNEP. United Nations, 5 June 1992, NA-92-7807, 24p.

VIEIRA, R. M. da S. P. Susceptibilidade à degradação/desertificação no semiárido brasileiro: tendências atuais e cenários decorrentes das mudanças climáticas e do uso da terra. 2015. 111 pf. Tese (Doutorado em Ciência do Sistema Terrestre) - Curso de PósGraduação em Ciência do Sistema Terrestre, Instituto Nacional de Pesquisas Espaciais, São José dos Campos, 2015. 